\title{
Middle School Teachers' Perception of Differentiated Instruction on Lower Third Student Achievement
}

\author{
Lyndon Fitzgerald Charles Sr. ${ }^{1,}$, , Michele Lorette Luard ${ }^{2}$ \\ ${ }^{1}$ Department of Education, Medgar Evers College, Brooklyn, USA \\ ${ }^{2}$ New York City Department of Education, Brooklyn, USA \\ Email address: \\ lcharles@mec.cuny.edu (Lyndon F. C. Sr.), mluard $a$ schools.nyc.gov (Michele L.) \\ ${ }^{*}$ Corresponding author
}

\section{To cite this article:}

Lyndon Fitzgerald Charles Sr., Michele Lorette Luard. Middle School Teachers' Perception of Differentiated Instruction on Lower Third Student Achievement. Teacher Education and Curriculum Studies. Vol. 3, No. 3, 2018, pp. 20-33. doi: 10.11648/j.tecs.20180303.11

Received: September 26, 2018; Accepted: November 10, 2018; Published: December 20, 2018

\begin{abstract}
Urban classrooms consist of diverse learners who access information through a variety of modalities based on proficiency levels. The purpose of this qualitative case study was to determine the relationship between middle school teachers' perceptions of differentiated instruction, utilization and implementation as a viable method to increase lower third student academic achievement. The semi-structured interview method was utilized for data collection. The relationship between teacher effectiveness in preparing and executing differentiated lessons to meet the needs of the lower third student population and middle school teachers' perceptions of differentiated instruction effect on the implementation and use of differentiated instruction are discussed. Teachers' perceptions of differentiated instruction as an instructional strategy to address students' needs in the planning and preparation of differentiated lessons affect implementation. Several challenges identified by middle school teachers in utilizing and implementing differentiated instruction to address the needs of lower third students adversely affects the intensity of rigor in learning environments. Differentiated instruction is critical to increasing students' readiness levels towards positive academic achievement. Results indicated that most middle school teachers are knowledgeable of differentiated instruction. Middle school teachers identify differentiated instruction as a critical instructional strategy that teachers should embrace to address the needs of the lower third student population. Teachers' perceptions of differentiated instruction as an instructional strategy to address lower third students' needs in the planning and preparation of differentiated lessons affect implementation.
\end{abstract}

Keywords: Differentiated Instruction, Middle School, Excessive Planning Time, Lower Third Student, Participant $=\mathrm{P} 1, \mathrm{P} 2, \ldots, \mathrm{P} 35, \mathrm{IEP}$

\section{Introduction}

The future of education is dependent on building capacity for all students' to attain significant academic achievement. Thus, it is imperative that educators ensure that students within any given learning environment attain high levels of performance [1]. A focus on increased learning capacity, coupled with well-designed learning experiences, is a critical factor in laying the foundation for increasing student performance and deliberately enhancing student academic achievement [2]. For students to achieve maximum levels of success, they must acquire new knowledge and behaviors, confidently draw on their interests, abandon old practices, and embrace new ones [3]. Educators are therefore called upon to embrace new ways of thinking to which students are responsive.

One highly recommended instructional method utilized for improving student achievement is differentiated instruction. Differentiated instruction is the practice of adapting materials, content, process, product, and assessments that meet the learning needs of the diverse learners in the classroom [4]. Educators are challenged to increase student's performance in the midst of high-stakes testing, such that, students perform to expected standards as they progress along grade levels [5]. The key to attaining the goal of student achievement depends on teacher belief in effectively implementing differentiated instruction as an instructional 
method to support the diverse student population in their classroom [6]. The perception of middle school teachers regarding differentiated instruction and its ability to improve student's academic achievement is of concern because teachers are reluctant to change their pedagogy from more traditional instructional methods [7].

As teachers engage students in daily activities designed to support access to content, they should keep in mind the varied abilities of the learners in their classrooms [8, 9]. The fact that standardized state assessments are constantly measuring student academic achievement, differentiated instruction is a viable strategy that teachers may utilize to ensure students meet promotional criteria [10]. In achieving promotional criteria, it is important to align students higher order thinking and relevance of the content to their real life experiences to increase classroom engagement and eventually academic achievement [11]. Increasing student's awareness of the relevance of learning will assist in improving their problem-solving skills and the realization of how such skills apply to real-world applications [12].

Attaining a level of student achievement is crucial in ensuring that lower third students (low performing students) achieve a level of academic success that results in increased understanding of grade level content [13]. Teachers' acceptance of differentiated instruction that incorporates targeted planning for the diverse student population is a much-desired mindset shift. Differentiated instruction strategies support student language and content acquisition, therefore it is viewed as a powerful tool in preparing all students for academic success [14].

Ensuring students' academic success, through consistent improvement of monitoring academic achievement, the focus has been on the instructional delivery and methods of assessment $[15,16]$. Developing and implementing rigorous instructional strategies that focus on individual student academic achievement as it pertains to closing the achievement gap is a much-desired goal of educators. Under the No Child Left Behind Act of 2001 the expected performance goals are defined in terms of Annual Yearly Progress (AYP). AYP identifies the minimum percentage of students required to score at or above the designated cut-off score in English Language Arts and mathematics in order for schools to meet AYP $[5,17]$. Students who do not meet the cut score requirement are often placed in Summer Academy to improve their content acquisition, attain proficiency, and avoid grade retention [18].

A recent and exciting reform to education has been the implementation of the Common Core State Standards (CCSS) to improve teaching, learning, and create academic success for all students [19]. The CCSS are a set of learning standards that provide a framework to foster higher level learning skills than those that have been developed by earlier standards [20]. CCSS focuses on higher level skill development acquired through appropriate instructional strategies that are more open-ended and less traditional, thus requiring students to provide evidence through a product that demonstrates the incorporation of higher order thinking skills
[21]. Studies have shown that test base accountability accompanying the CCSS initiative through the implementation of high stakes testing, and performancebased type items that are open-ended require a higher degree of effort on the student's part to complete. The outcome has been a variety of perverse results, even though there has been evidence that measurable gains have been realized $[19,20$, 22]. With this in mind, there is a need for an effective instructional strategy that is capable of moving the achievement needle.

Educators at the state, local and district levels have been under tremendous pressure to focus on teaching methodologies that are student-centered and support student content acquisition $[23,24]$. Instructional strategies such as differentiated instruction, workshop model, cooperative learning, peer tutoring, and computer-assisted learning have been implemented as instructional vehicles to enhance student achievement [25]. Adapting an instructional method designed to attain desired student outcomes is a crucial component to ensure that individual student needs are met [26]. Implementation of new instructional strategies that are appropriate, highly effective in student engagement, advance student achievement, increase the focus on teacher development, and support teacher efficacy is an essential facet in supporting individual student outcome [6]. Such efforts provide appropriate tools that are designed to assist teachers adequately meeting the needs of all students [27].

Currently, schools face the challenge of implementing new outcomes based on new mandates that are aligned with State Standards. These outcomes and standards have resulted in a single set of learning requirements for all students creating an interesting challenge for educators. A significant concern that arises is whether learning outcomes are to be the same for all students and whether the instruction should be the same for all students regardless of their proficiency levels [28]. The immediate concern lies in finding effective instructional strategies that provide the necessary skill sets to improve the academic achievement of students listed in the lower third citywide. The lack of academic achievement of the lower third students result in an impedance of vertical movement, thus, their struggle to attain higher proficiency levels [29]. Improving student's proficiency levels such that level 1 students attain level 2 proficiency, level 2 students attain level 3 proficiency, and level 3 students attain level 4 proficiency is a significant concern in students' annual academic growth throughout New York City middle schools [30].

In urban environments, student population represents a dense concentration of students from numerous cultures that coalesce in a relatively small area imposing their cultural differences on each other and the learning environment [31]. This situation creates unique challenges for teachers. Teachers are forced to acknowledge the distinct differences in the students' characteristics and use their knowledge of each student's background to plan purposeful lessons that are specific to individual students or group of students [32]. It is imperative that teachers get to know their students and utilize 
any acquired knowledge of their strengths and weaknesses to create activities that are of interest to those students. Research shows when students' interests are at the forefront of teacher planning and preparation, it is possible to fully engage students thus enhancing their academic performance over time [33].

Despite the availability of new and innovative instructional strategies such as cooperative learning, peer-assisted learning, and differentiated instruction, teachers, continue to rely on whole group instruction that neglect the individualized needs of the diverse student population [34]. While differentiated instruction is the most touted instructional method for addressing the needs of the diverse student population in a given learning environment, the instructional method is rarely understood by teachers [35]. As schools struggle to bring all students up to the minimum proficiency level, tailoring instruction to meet individual student needs and provide adequate support must be a focus to ensure that the challenge is being met [36]. Reference [10] discussed the fact that as schools focus on remediation for struggling students, such action places an inadvertent limit on the degree to which teachers can differentiate. Improving achievement for all learners in the middle grades, with specific attention to the needs of students who are in the lower third, requires implementation of an interest-based, rigorous approach to instruction that inevitably guarantees all students will attain proficiency [37].

This study examined teachers' perceptions regarding the implementation, use, and potential effect of differentiated instruction on the overall improvement in the annual academic achievement of the lower third students in the middle schools located in District 17 in Brooklyn, New York. Several studies investigated teacher self-efficacy, professional development, and students with disabilities regarding differentiated instruction learning strategies; however, an investigated of middle school teachers' perceptions regarding the effect of differentiated instruction on lower third middle school students' academic achievement is warranted $[2,6,15,38]$. It is important to note that while a combination of teaching methodologies have been utilized to increase students' achievement, differentiated instruction is a highly promoted and utilized teaching strategy that is believed to be the solution in achieving this goal [32]. Reference [39] showed that increasing the academic achievement for lower third students, hinges on educators adapting an instructional strategy, such as differential instruction as the primary instructional tool to realize measurable outcomes. Additionally, reference [40] have shown that improving students' academic level is dependent on replacing traditional instruction with differentiated instruction.

\section{Method}

In this research study, the sample size consisted of 35 middle school teachers of English Language Arts and mathematics in four middle schools in District 17 located in the Brooklyn, New York. The data for this study includes in person, one-on-one interview of each participant. The study utilized the semi-structured interview protocol that ensured depth over breath of meaning, acquiring new insights, and foster a deeper understanding of bringing the unknown into the realm of the known, while learning about them in detail $[41,42]$. The results from the data were derived from the analysis of transcribed handwritten notes supported by audio recordings. The transcribed notes were uploaded and coded using Nvivo 11 Pro Software. This procedure allowed for consistent reliable and comparable data collection throughout the process.

\section{The Study}

Three research questions drove the study. Randomly selected middle school teachers participated in one-on-one interview sessions by responding to the following three questions. Q1. What are middle school teachers' perceptions regarding the use of differentiated instruction to increase lower third student academic achievement? Q2. How do middle school teachers view the relationship between teachers' effectiveness in preparing and executing lessons that are differentiated to meet the needs of the lower third student population? and; Q3. How do middle school teachers' perceptions of differentiated instruction affect their implementation and use of differentiated instruction? These question provided a pathway to determine the effect of middle school teachers' perceptions regarding differentiated instruction and its effect on the lower third student population. Interview questions were formulated to capture specific elements of the participants' mindset regarding students achievement based on ways belief affect teacher's use of differentiated instruction to address the lower third student academic achievement.

\section{Data Analysis}

A total of 35 teachers participated in the one-on-one interview sessions. Table 1 shows the demographic data of the participants. Table 1 indicates that $54.3 \%$ of the participants were female and $45.7 \%$ were male teachers. The participant's ethnicity was representative of the students/residents in the schools geographic location. Ethnicities included: African American, Black $\backslash$ West Indian, Caucasian, Hispanic, and Israelite.

Table 1. Ethnicity and Gender of Population Sample.

\begin{tabular}{ll}
\hline Participants & Percentage (\%) \\
\hline African American & 54.3 \\
Black/West Indies & 11.4 \\
Caucasian & 11.4 \\
Hispanic & 5.7 \\
Israelite & 5.7 \\
North African & 5.7 \\
Gender & \\
Male & 45.7 \\
Female & 54.3 \\
\hline
\end{tabular}


Table 2 shows the educational demographics of the participants. The grade level taught by the participants ranged from sixth grade to eighth grade. $48.6 \%, 45.7 \%$, and $5.7 \%$ teach English Language Arts (ELA), Mathematics, Science and Mathematics respectively. The teaching experience of the participants ranged from five years to greater than 15 years of service. Two participants hold a Ph.D. degree, and 33 hold a master degree in their area of certification. Since all participants had five or more years of classroom teaching, it suggests that they have classroom management under control and were able to implement differentiated instruction in their class.

Table 2. Academic Background of Sample Population.

\begin{tabular}{ll}
\hline Years of Service & Percentage $\mathbf{( \% )}$ \\
\hline$>5$ years & 37.1 \\
$>5$ years & 45.7 \\
$>15$ years & 11.4 \\
Level of Education & \\
Masters & 94.3 \\
Doctoral & 5.7 \\
Certification & \\
ELA & 48.6 \\
Math & 45.7 \\
Science/Math & 5.7 \\
\hline
\end{tabular}

The data was loaded into Nvivo 11 and coded based on the observed themes. The study sought to determine middle school teacher's perceptions of differentiated instruction effect on lower third students' academic achievement. Coding of the data produced three themes from question 1. The themes that emerged were: support for lower third students, targeted instruction, and addressing diverse student needs. Three themes emerged from question 2: utilizing differentiated instruction as an integral part of the lower third students learning process; time is a factor in planning differentiated lessons, and differentiated instruction, when implemented properly, can enhance learning for the lower third population. The themes that emerged from question 3 were: differentiated instruction strategies apply to all students in the lower third; differentiated instruction help teachers design rigorous lessons for lower third students; and differentiated instruction results in lower third student's success over time. Additionally, three subthemes that emerged were: 1) differentiated instruction is a good instruction strategy that effectively addresses the needs of the lower third students, 2) there is a need to target the lower third population to create a level of measured success, and 3) lower third population must be targeted to address student needs through differentiated instruction.

\section{Findings}

Q1. What are middle school teachers' perceptions regarding the use of differentiated instruction to increase lower third student academic achievement? Interview data indicate that three general themes emerged. The themes that emerged were: support for lower third students, targeted instruction, and addressing diverse student needs.
Theme 1: Support for lower third students. The data collected from the interviews indicate, participants viewed differentiated instruction as an instructional "tool" that is helpful in meeting the needs of the lower third students. To this effect P21 explained that differentiated is essential to addressing the students need on a daily basis especially with the diverse cultures present in the classroom. P21 stated: "Differentiated instruction definitely can be helpful in addressing the needs of students listed in the lower third by focusing on content and language acquisition so that they become critical thinkers as they get a better hold of the content." P29 and P31 echo this sentiment in that they believe differentiated instruction is extremely powerful in ensuring that all student in the learning environment are met at their level and nurtured by providing targeted instruction that allows them to realize academic success. P30 stated: "I think differentiated instruction can provide a teacher with strategies that meet the individual needs, weaknesses, and strengths of each student although this is difficult in large classes. Differentiated instruction allows teachers to create purposeful grouping then target individual group with appropriate strategies that result in efficient use of resources to move the student to higher levels of learning. In support of P21 and P29, P31 stated: "I think that differentiated instruction provides me with the power to implement strategies that are helpful in assisting the lower third student's attainment of mastery. Lessons are planned to meet the needs of the lower level students not just the top performing students.

Theme 2: Targeted Instruction. Two central beliefs were constant with two-thirds of the participants' perceptions. Table 3 shows the distribution of the participant's responses. Participants strongly believe differentiated instruction is essential in generating student's success, and differentiated instruction is an effective instructional strategy to support lower level learners' success. P25 stated: "Overall differentiated instruction allows teachers to meet students where they are and give them an opportunity to engage in rigorous learning. It is an opportunity to help the students achieve success." P17 stated: "Differentiated instruction is a great technique to use for engaging students at all levels. It is important to try to reach all students in many different ways. For example, using computers, books, and lessons that hone in on their strength and interests should be considered when differentiating materials. During lessons, some of the students create drawings, create poems, and connect with art. It brings out their strength and provides a sense of ownership. Most of the time students engage in activities that address their interests." In support of the other participants, P5 stated "It is helpful. Differentiated instruction can take many different forms. Specially targeted and scaffolding instruction spins off differentiated instruction. It gives students the confidence to compete at their level." Over half of the participants cited the fact that differentiated instruction provides the platform to design targeted lessons that address the needs of the lower third student population to improve academic success. 
Table 3. Students Success Through the Use of Differentiated Instruction from Teachers' Perceptions.

\begin{tabular}{ll}
\hline Differentiated Instruction & Percentage (\%) \\
\hline Generate Student Success & 65.7 \\
Effective Strategy & 65.7 \\
Does not Generate Success & 34.3 \\
Is not an effective Strategy & 34.3 \\
\hline
\end{tabular}

Theme 3: Addressing diverse student needs. Participants responses describe differentiated instruction as a must use instructional strategy in classrooms across the district. P8 stated: "Definitely, differentiated instruction is the key to addressing the needs of individual students... kids learn at a different pace and learn differently. The kids also have different backgrounds, so they do not all have the foundation. They have little self-confidence, so you have to go down to their level and build them up. It is a no-brainer. Following that same thought process, P21 stated: "Differentiated instruction is a must, it allows for a better knowledge of the students. Teachers must know their student's performance levels to effectively differentiate for them individually. It is not just for the lower third and the special education students as some people may think. While it enables the lower third students to meet standards, it also helps higher level students to achieve their goals as well. In this way differentiated instruction is a powerful teaching tool". Echoing the perception that differentiated instruction provides a platform to address individual student's needs through targeted instruction based on individual student strength, P31 stated: "Research has proven that all students learn differently. Therefore, traditional strategies would only meet the needs of some students. Hence, the choice to implement differentiated instruction so every student will learn the concept being addressed."

Q2. How do middle school teachers view the relationship between teachers' effectiveness in preparing and executing lessons that are differentiated to meet the needs of the lower third student population? Interview data indicate that three general themes and one subtheme emerged. The themes that emerged were: utilizing differentiated instruction as an integral part of the lower third students learning process; time is a factor in planning differentiated lessons, and differentiated instruction, when appropriately implemented, can enhance learning for the lower third population. The subtheme generated addressed the need for adequate differentiated instruction professional development for teachers.

Theme 1: Utilizing differentiated instruction as an integral part of the lower third students learning process: There was a high degree of agreement amongst the participants regarding the fact that differentiated instruction should be an integral part of planning lessons for the lower third students. This perception is amplified by $\mathrm{P} 1, \mathrm{P} 8, \mathrm{P} 11$, and P29. To support this perception, P1 stated: "Differentiated instruction is one of the best instructional tool a teacher can use. It is helpful to assist all students especially the bottom third students. If all teachers have a model to see how effective it is, then they would see that the strategy can move students' academic success. You have to understand differentiated instruction, see its importance to want to use it." P8 support P1 belief that differentiated instruction is one of the best tools available to teachers for reaching the lower third student's academic needs. P8 stated: "Differentiated instruction is imperative. It is not what we think we thought, but what the students learn. You have to know the child learning level to select the appropriate text. Differentiated instruction is important, however the socioeconomic piece tend to be overlooked. Teachers must consider providing emotional support to students as well." P11 stated that differentiated instruction is the best instructional strategy that can be utilized to reach individual students. "Differentiated instruction is the best way to reach individual students who are at different levels of understanding a concept." P29 support this perception by stating: "Differentiated instruction can be executed in a way that honors students' strengths and weaknesses. Attending to student's backgrounds, interests, personal and national history, and selecting content that caters to all of the above can lead to rich lessons and individual learning outcomes."

Theme 2: Time as a factor in planning differentiated lessons. A majority of the participants cited the fact that time is a factor in planning and preparation in regards to differentiating lessons for the lower third student population. P7 stated: "It requires a lot of time for preparation-it is a tedious process." P22 stated: "Rigorous and effective lessons requires through planning. Time is also a major factor. Planning time encroaches on my personal time and my family time, however, planning time is crucial to differentiated instruction. Unfortunately, there is not enough time to effectively plan for it to be always rigorous and effective. Depending on the topic, at times there is both rigor and effectiveness and at other times there is only one." P16 and P31 stated their concerns that time is also viewed as a factor in planning and preparation, but planning is necessary. Both participants focused on the fact that for effective implementation of differentiated instruction to take place, teachers need to plan. "It is a lot of work. It is hard to do every single lesson, especially when student's background, interest, and learning levels are not well known."

Theme 3. Differentiated instruction, when implemented properly, can enhance learning for the lower third population. Many participants expressed their concerns regarding the "correct" implementation of differentiation to enhance lower third student's success. P3 stated: "If implemented correctly, differentiated instruction can move lower third students across proficiency levels. Once students are engaged in learning in their own way as opposed to learning being forced upon them, their learning can be enhanced. Differentiated instruction lends to learning/acquiring the content in their own way." Similarly, P26 stated: "When implemented correctly differentiated instruction enhances the learning process for the lower third student population. When students are met at their proficiency level, teachers access their learning in such a way that they feel a part of the process as they become involved, but it must be done correctly to be of benefit to the student." Supporting this 
theme P27 stated: "If carefully crafted and teachers develop a clear understanding of the limits and benefits then differentiated instruction can be leveraged to improve academic outcomes."

One subtheme generated from this research question highlighted the need for adequate professional development in differentiated instruction strategies. P1, P18, P21, P26, \& P33 stated; for a teacher to effectively differentiate their instruction for the lower third students, they need high quality professional development to fully understand its importance in their daily practice. P1 stated that: "Teachers have to understand differentiated instruction, see its importance to want to use it." P18 stated: "Differentiated instruction is needed in all classrooms and at every level of proficiency. It is a powerful strategy, but not all educators understand it. Professional development is needed to increase teacher knowledge." P21 voiced a strong belief that teacher need to be provided with a series of professional development. "It is imperative to train teachers to use and implementation of differentiated instruction. Teachers do not get the professional development to support them to implement differentiated instruction effectively." P26 in support of professional development training stated: "Teachers need to be trained more in differentiated instruction strategies. It is something that administration need teachers to use, but most teachers do not know how to do it, and they do not necessarily get the support. Overall, teachers need more support. It is good to provide students with a variety pathways during the learning process, but teachers need to know how to do so effectively."

Q3. How do middle school teachers' perceptions of differentiated instruction affect their implementation and use of differentiated instruction? Analysis of the interview data indicates that three themes and two subthemes emerged. The themes that emerged were: differentiated instruction strategies apply to all students in the lower third; differentiated instruction help teachers design rigorous lessons for lower third students; and differentiated instruction results in lower third student's success over time. Additionally, the subthemes that emerged were: differentiated instruction is an excellent instructional strategy that is useful in addressing the needs of the lower third students and; there is a need to target the lower third population to create a level of measured success.

Theme 1: Differentiated instruction strategies applies to all students in the lower third. Majority of the participants strongly believe that differentiated instruction is a strategy that allow teachers to address the needs of the lower third students. Participants shared their belief that the instructional strategy must be used for all students in their classroom and not a selected few. P1 stated: "Differentiated instruction definitely help those who need the help, but most importantly it is effective in helping all students in the classroom-it is helpful to everyone." P3 response paralleled that of P1 by stating: "It means targeting all learners. Differentiated instruction should be incorporated to meet the needs of lower, middle, and upper third students." P5 and P8 also shared their insights that differentiated instruction must address all students who are present in the learning environment to access content by stating: "Differentiated instruction is not only for the struggling students, but it also addresses the needs of the accelerated students as well. It not only move students forward through scaffolding of content, process, and product but it addressed the lower third through targeted instruction." P8 stated: "Based on my perception of differentiated instruction, it effectively addresses the needs of all students. While most teachers focus on the lower third, they also have to address the average and higher level students, so all students register growth." P12 stated: "Teachers must plan lessons designed to reach all students then think about all possible misconceptions or errors students may encounter and design rigorous assessments to address those misconceptions and errors. At the same time teachers must focus on designing challenging work for the higher level learners to address their needs, not just creating more work."

Theme 2: Differentiated instruction help teachers design rigorous lessons for lower third students. In addressing teachers' perception differentiated instruction affect their use and implementation of the instructional strategy in the classroom, teachers provided the following insights. P9 stated: "Differentiated instruction allows teachers to increase student's critical thinking skills. Increasing the rigor results in vertical movement to higher proficiency levels. P14 stated: "It can, but does not guarantee that there will be more rigorous lessons. Differentiation without a purpose may produce ineffective lessons. This does not benefit the students and does not create a rigorous lesson or rigorous learning environment. When done correctly, differentiated instruction lead to many aha moments that make things click for the students." P16 stated: "The ultimate goal of the teacher is to teach students how to think critically as they engage in learning. Traditional teaching methods are bathe in rote memorization-they develop students in the way of memorization. Differentiated instruction, on the other hand, allows students to "learn how to learn", thus breaking up the rote memorization process." P29 indicated that differentiated instruction serves the purpose of enhancing rigorous instruction. P29 stated: "Differentiated instruction does not reduce rigor, it enhances rigor. Differentiated instruction is used to help students easily and meaningfully access content and learn specific skills." P31 stated: "Differentiated instruction requires more planning and more in-depth analysis, so it has the potential to be rigorous and effective based on students level and the data that will inform where students are in the learning process."

Theme 3: Differentiated instruction results in lower third student's success over time. The recorded responses indicate that $66 \%$ of the respondents believed that differentiated instruction was instrumental in fostering student's success over time. P4 stated: "When differentiated instruction is employed in daily lessons and every student take the same test each year, there is measurable gains in the lower third students test scores. Those students with special needs 
achieve a certain level of success. The achievement they realize is a result of a differentiated instruction used throughout the school year." P17 stated: "Students often come to me as a level 1. Planning for then usually include the use differentiated instruction, by the end of the year they move to higher proficiency levels. With differentiated instruction, most of the student achieve some level of success." Similarly, P19 stated: "There have been positive student growth on state exams. Usually there are a few low functioning students at the beginning of the school year. Only a few students would write the exam, but that has increased as an understanding of differentiated instruction is attained. Now $90 \%$ of the students are taking the exam and achieving success." P21 stated: "Yes, differentiated instruction foster students success. Students with an individualized education plan (IEP) who never, ever passed a state exam have experience success. Through differentiated instruction attention is paid attention to learning styles and students are challenged to think critically by varying the content, process, and product, but not all the same time. Through the utilization of differentiated instruction most students are knowledge and content ready and performed well enough, based on ability to secure a passing grade."

The first subtheme that emerged from this question supports the participant's perceptions that differentiated instruction was effective for the lower third student progress. Several of the participants strongly believe that differentiated instruction improves fluency, accuracy, and comprehension skill of the lower third student's population. This is supported by data derived from the perspective that show measurable level of improvement on scores from state exam. The second subtheme indicates that participants believe that targeted differentiated instruction is crucial for lower third student's success. Table 4 demonstrates the distribution of participant's responses concerning the subthemes.

Table 4. Distribution of Participant's Responses concerning Subthemes.

\begin{tabular}{lll}
\hline Differentiated Instruction Building Students Capacity & & \\
\hline & Percentage (\%) Yes & Percentage (\%) No \\
\hline Differentiated Instruction to Strengthen Skillsets & 62.9 & 37.1 \\
Targeted Differentiated Instruction is Crucial for lower Third Student Learning & 68.6 & 31.4 \\
\hline
\end{tabular}

The responses from this subtheme indicate that teachers believe there is a marked improvement in the achievement of the bottom third student population when students are taught to think critically using differentiated instruction as measured by local and state assessments. Participants stated that engagement is critical to sustaining the lower third student academic growth. Additionally, participants noted, students' were beneficiaries of achieving success when teachers are aware of their needs and incorporate differentiated instruction in their planning and preparation to address those needs. To this end, several of the participants indicated that they observed measurable gains as student's progressed across grade levels.

\section{Results}

What are middle school teachers' perceptions regarding the use of differentiated instruction to increase lower third student academic achievement? The information recorded from the interviews showed that middle school teachers believe that differentiated instruction is a crucial pedagogical strategy. Moreover, participants strongly believe that differentiated instruction should be used in every classroom to address the needs of the lower third students to improve their academic achievement. Reference [10] argued that the utilization of differentiated instruction to address low performing students achievement resulted in higher scores and increased comprehension.

The results of the study indicate that teachers' perceptions strongly supported the belief that differentiated instruction is a critical facet in addressing the needs of the lower third student population. Most of the participants agreed that differentiated instruction focus on support for the lower third student population is a necessary instructional strategy to enhance their learning process. Reference [43] acknowledged that teacher planning for a diverse population in their classroom must achieve the goal of helping students attain success by addressing individual needs. The data indicates that most participants interviewed, believe that in order to address the needs of the lower third student population, planning and preparation must be targeted to create a culture that focuses instruction that target the diverse student population. Reference [38] argued that differentiated instruction focuses on addressing the readiness, learning styles, abilities, and preferences of students that allow teachers to address these individual differences.

Finally, middle school teachers perceptions indicate that addressing the diverse needs of the student population can make a difference in assisting all students in the learning environment achieve their highest potential. Most participants interviewed echoed the sentiment that in their classroom, there is a growing student population that has become increasingly culturally diverse. As a result, it is nearly impossible to teach a lesson without differentiating the content, process, or product in order to meet students' needs. Current literature supports this finding from the perspective that addressing the diverse learning modalities in the classroom, lessons must be differentiated to meet those needs [44]. Such diverse student population suggests that teachers must rely on higher levels of differentiation, more opportunities for enrichment, and grouping that is designed to challenge all students [44].

How do middle school teachers view the relationship between teachers' effectiveness in preparing and executing lessons that are differentiated to meet the needs of the lower third student population? The results of this research question 
yielded three important perspectives that provided a deeper insight into the participant's mindsets. The first theme that emerged was teachers' perceptions of utilizing differentiated instruction as an integral part of the lower third student learning process. This belief supports literature relating to the knowledge of students, such that, planning can occur around appropriated text related to personal and national interests that result in rich lessons and positive learning outcomes. To differentiate appropriately for students, it is imperative that teachers know their students. It is impossible for teachers to make the content relevant to their students in the absence of knowing their interest, learning styles and culture [45]. Additionally, teachers believe that adequate professional development is needed to heighten their ability to utilize and implement the strategy effectively. With this said, it is paramount that teachers are mindful that differentiated instruction focuses on how to differentiate and why differentiated instruction is necessary [6].

The second theme addressed the importance of time as a factor in the planning and preparation of differentiated lessons. This finding highlights the importance participants place on designing effective differentiated instruction lessons. Reference [46] acknowledged the fact that teachers and teacher teams, need adequate time to support the use of data to create summative and formative assessments that support checking for understanding. The acquired data may then be used to inform planning of differentiated instruction lessons that are timely and support specific needs.

The third theme highlighted the enhancement of lower third student achievement when differentiated instruction is appropriately implemented. Participant's belief indicates that differentiated instruction dramatically enhances the lower third student population content acquisition. As a result it has been noted that without specific information of the learners, planning for effective differentiation will likely be compromised [47].

How do middle school teachers' perceptions of differentiated instruction affect their implementation and use of differentiated instruction? Three themes were generated from the responses provided by the participants. The first theme provided insight into the teachers' perceptions regarding differentiated instruction to teach all students. Participants believed that since the lower third students are grouped with middle and upper third students, teachers must address the needs of all students as well as their academic success. Reference [48] supports the argument that adopting differentiated instruction will assist teachers in providing the support needed to address the differences in students learning profiles.

The second theme derived from the data addressed the participant perception regarding the ability of differentiated instruction to assist teachers in designing rigorous lesson for lower third students. Most of the participants voiced the opinion that by addressing individual student needs teachers can plan lessons that are rigorous based on the student's proficiency levels. To address the rigor in instruction the concept of teaching up must first be considered [49]. The teacher plan with a higher level in mind then differentiate or scaffold in ways to support a broader diverse student population [50].

The third theme addressed the lower third student success over time. More than half of the participants acknowledge the fact that over time, differentiated instruction results in measurable student success. The findings from this theme suggest that most teachers embrace the belief that long-term exposure of the lower third students to differentiate instruction results in student achieving success as they move along the learning continuum.

Two subthemes emerged from research question 3 . Subtheme 1 addressed the belief that differentiated instruction is a good strategy for addressing the lower third student population deficiencies. Reference [51] acknowledged the importance of differentiated instruction to address the need of low performing students by providing the ability to vary standards while receiving the same instructional focus. The second subtheme to emerge from this question addressed participant's belief that the lower third population must be targeted to address their needs effectively. Research show that differentiated instruction grounded in students learning preferences will provide clear pathways to curriculum revision that addresses specific student need [52].

Table 5 shows the participant's perceptions regarding mindset for the themes that emerged from interview questions for research question 1 . Theme 1 data confirms $77 \%$ of the participants believe that differentiated instruction provide support for the lower their students while $23 \%$ did not. Theme 2 data confirms $71 \%$ of the participants believe that target instruction was effective in meeting the lower third student's needs while $29 \%$ did not. Theme 3 data confirms $74 \%$ of the participants believe that differentiated instruction addressed the diverse needs of the lower third students in their class while $26 \%$ did not.

Table 5. Participants Perceptions of Research Question 1.

\begin{tabular}{lll}
\hline Theme & \%o of Participants & \\
\hline & Y & N \\
\hline 1 & 77 & 23 \\
2 & 71 & 29 \\
3 & 74 & 26 \\
\hline
\end{tabular}

Note. $\mathrm{N}=$ no. $\mathrm{Y}=$ yes.

Table 6 shows the data of participant's perception regarding their mindset for the themes that emerged from interview questions for research question 2 . Theme 1 data confirms $77 \%$ of the participants believe that the utilization of differentiated instruction was an integral part of the lower third students learning progress while $23 \%$ did not. Theme 2 data confirms $71 \%$ of the participant's support the belief that time was a factor in planning differentiated lessons while $29 \%$ did not. Theme 3 data confirms $94 \%$ of the participants believe proper implementation of differentiated instruction can enhance the learning for the lower their student's population while $6 \%$ did not believe that differentiated instruction was a useful tool to enhance learning. 
Table 6. Participants Perceptions of Research Question 2.

\begin{tabular}{lll}
\hline Theme & \% of Participants & \\
\hline & Y & N \\
\hline 1 & 77 & 23 \\
2 & 71 & 29 \\
3 & 94 & 6 \\
\hline
\end{tabular}

Note. $\mathrm{N}=$ no. $\mathrm{Y}=$ yes.

Table 7 shows the data of participant's perceptions regarding their mindset for the themes that emerged from research interview questions that addressed research question 3. Theme 1 data confirms $77 \%$ of the participants believe that differentiated instructional strategies apply to all student in the lower third while $23 \%$ did not support that belief. Theme 2 data confirms $71 \%$ support of the participants the belief that differentiated instruction help teachers plan a rigorous lesson for the lower third students while 29\% did not support. Theme 3 data confirms $94 \%$ of the participants believe differentiated instruction strategies results in lower third student's success over time while $5.7 \%$ did not.

Table 7. Participants Perceptions of Research Question 3.

\begin{tabular}{lll}
\hline Theme & \%o of Participants & \\
\hline & Y & N \\
\hline 1 & 77 & 23 \\
2 & 71 & 29 \\
3 & 94 & 5.7 \\
\hline
\end{tabular}

Note. $\mathrm{N}=$ no. $\mathrm{Y}=$ yes.

The participant's interviews generated themes, subthemes, and patterns regarding teachers' perceptions, attitudes, and concerns about differentiated instruction. The data generated a total of nine themes, three from each research question and three subthemes. The information generated from the themes provided a more in-depth understanding of middle school teachers perceptions regarding differentiated instruction and its impact on the achievement of the lower third student population.

\section{Discussion}

The study provided rich and in-depth interviews with 35 participants who provided data that was extensive and represented their individual perceptions and knowledge of differentiated instruction. Analysis of the data derived from the interviews suggests that many of the participants regard differentiated instruction as a teaching strategy that can effectively address the needs of the lower third student population.

Research Question 1: What are middle school teachers' perceptions regarding the use of differentiated instruction to increase lower third student academic achievement? The data derived from this question yielded three significant findings: 1) differentiated instruction to support lower third students learning, 2) targeted instruction for lower third students, and 3) addressing diverse student's needs. The implications of these findings are indicative of how middle school teachers perceive the importance of differentiated instruction to address the needs of the lower third student population in their learning communities.

The implication of these findings indicates that middle school teachers explicitly believe that differentiated instruction as an instructional strategy is crucial in addressing the diverse ability of students in the learning environment especially when addressing the lower third student population. Reference [53] argued for the importance of providing multiple pathways for a diverse student population that is indigenous to the urban student population as a critical factor in creating strategies that will improve student's ability to master grade level work. This model of teaching must focus on the students' readiness levels, interests, and learning styles manifested by the students to support their learning goals [54].

The second finding, targeted instruction for lower third students, revealed that teachers strongly believe in addressing the lower third student population by inculcating differentiated instruction. However, their specific needs must be targeted to improve their individualized academic achievement. Teachers are aware of the growing population of students with disabilities and English Language Learner's that present schools with a unique problem. Teachers, therefore, realize the increase of these two population directly increases the learning diversity in classrooms. This finding implies that middle school teachers are becoming acutely aware of the needs to adequately address students' academic achievement, as a result, teachers must incorporate differentiated instruction to affect the student's educational needs. Additionally, teachers view addressing targeted learning through the use of differentiated instruction as a viable pathway to access the rich variety of learning styles, cultures, and proficiency levels of the students they support. Reference [16] acknowledged that teachers must master the analysis and utilization of student data to effectively plan and deliver lessons that are designed to increase the skills that result in realistic academic achievement. Reference [55] argued that educators are charged with the task of developing and implementing strategies that will ensure appropriate measures are put in place to support the success of the diverse student population. Differentiated instruction provides teachers with the tools necessary for addressing student's readiness levels which is a function of their varied abilities [56]. Furthermore, it is important to note that differentiated instruction is a deliberate attempt to planning and teaching that will provide multiple pathways to address students learning that address specific students' needs and goals $[14,57]$. With this in mind, pre-service and in-service teachers should take into account the differences in students' learning abilities and utilize targeted learning, promoted by differentiated instruction, to bolster an increase in student learning [58].

The third finding, addressing diverse students' needs, highlighted the importance of teacher's knowledge of each student and their ability to recognize that in order to assist the diverse students they must know what factors need to be 
addressed to move students along the learning continuum. This finding implies that middle school teachers must have a working knowledge of their students' academic abilities if they are to plan appropriately to meet their individual needs. Reference [59] showed that when students are aware that teachers are making an effort to individualize instruction to meet their needs, they are more likely to take an interest in their learning. Reference $[56,60]$ acknowledged the fact that when students' needs are addressed through a differentiated curriculum, students tend to demonstrate significantly higher achievement than those students taught with a nondifferentiated curriculum. Differentiated instruction, therefore provide students with choices and viable pathways for commitment to their learning [14].

Research Question 2. How do middle school teachers view the relationship between teachers' effectiveness in preparing and executing lessons that are differentiated to meet the needs of the lower third student population? The data obtained from this research question identified three significant findings: 1) utilizing differentiated instruction as an integral part of the lower third students' learning process, 2) time as a factor in planning differentiated lessons, and 3) differentiated instruction when properly implemented can enhance learning of the lower third population.

The first finding indicate the importance of utilizing differentiated instruction as an integral part of the lower third students learning. Analysis of the data suggested teachers' belief is grounded in the fact that to effectively support the lower third student population (ensure they achieved academic success) it is imperative that teachers employ the use of differentiated instruction in their planning and preparation. This finding correlates with current research that acknowledges the importance for teachers to plan and prepare lessons that are appropriate, relevant, and effective in increasing the learning experience of all students [2, 61]. While many students in the learning environment strive to attain mastery of the content, their ability to accomplish this goal is a function of the teacher's ability to provide the necessary support that address individual student needs [62].

The second finding indicates the importance of time as a factor in planning differentiated lessons. Analysis of the data suggests that the participants believe effective implementation and practice of differentiated instruction to address the needs of the lower third student population requires significant time for planning and preparation. The implication of this finding further suggests the need to provide teachers with adequate time to engage in planning lessons that address individual student needs. With this in mind, teachers need support regarding the time required for teacher and teacher teams to engage in planning and preparation of differentiated lessons and tasks [46]. Time is flagged as a factor, in that, extensive time is needed to use a variety of assessment methods when the key factor is timely and focused intervention to support individual student needs $[46,63]$.

The third finding indicate that when implemented properly differentiated instruction can enhance learning for the lower third population. $65.7 \%$ of the teachers who participated in the study believe that differentiated instruction was effective in addressing the needs of all students in the learning environment when differentiated instruction lessons are well planned and effectively implemented. Analysis of classrooms indicated that there is a rich array of diverse students in urban learning environments resulting in teachers being challenged to provide information in a variety of forms [64]. Research indicate that students who are taught using differentiation demonstrate significantly higher achievement than their peers taught in non-differentiated environment $[56,60]$.

Additional analysis of the data indicated that the participants believe teachers must receive ongoing professional development to fully understand and implement the use of differentiated instruction. Reference [2, 61] argue the importance of providing teachers with appropriate support to ensure that they are effective in planning appropriate, relevant, and effective lessons. To achieve this goal, teaching practitioners must engage in professional development that fosters the use of differentiated instruction $[65,66]$. The research showed that when teachers engage in professional development that addresses the needs of diverse learners in respect to proficiency level and learning styles student engagement and achievement is attained. This further suggests that when teachers are provided with appropriate professional development in differentiated instruction, the desired student outcomes in regards to student academic achievement is realized.

Research question 3. How do middle school teachers' perceptions of differentiated instruction affect their implementation and use of differentiated instruction? The data derived from the interviews produced 3 findings: 1) differentiated instruction strategies apply to all students in the lower third; 2) differentiated instruction help teachers design rigorous lessons for lower third students; 3) differentiated instruction results in lower third student success over time.

The first finding, differentiated instruction strategies apply to all students in the lower third indicates that middle school teachers' perception of differentiated instruction as an instructional strategy applies to all students in the lower third. $68.6 \%$ of the participants hold strong beliefs in support of this finding. The finding correlates with current literature supporting the fact that participants believe differentiated instruction is an effective method in supporting lower third student academic performance [49]. Research has shown that students prefer to access information from a variety of modalities based on their learning styles, readiness level, and interests. When these aspects of teaching are considered, the need of the diverse student population in urban school would be adequately addressed [4].

The second finding differentiated instruction help teachers design rigorous lessons for lower third students is supported by $71 \%$ of the participants who believe that differentiated instruction assisted teachers in designing lessons that are rigorous and effective in supporting the lower third students learning. This finding implies that middle school teachers must utilize differentiated instruction to plan for students 
based on readiness levels to provide individualized instruction that support student readiness level. Data analysis indicated that the teachers firmly believe that differentiated instruction is instrumental in assisting teachers in planning and preparing lessons that are rigorous. However, the rigor should be based on students' readiness level if movement of student's readiness level from one proficiency level to another is the desired goal [67]. The goal of differentiated instruction is to provide every student with pathways to language and content acquisition that results in rich learning experiences that are rigorous, relevant and results in learning that move the students along the learning continuum such that their needs are appropriately addressed. Compared to the traditional teaching strategies that do have their advantages, differentiated instruction takes into consideration varying learning styles and allow for planning of unique lessons that address specific skillsets to advance learning [4].

The third finding addressed middle school teachers' belief that differentiated instruction results in lower third students' success over time. $94 \%$ of the participants strongly believed that when implemented over time, differentiated instruction is instrumental in fostering positive academic growth amongst middle school students, resulting in their continued academic growth. Reference [43] argued that teachers reported differentiated instruction practices result in significant student achievement and may serve as a predictor of academic growth. Working with students who are in the lower third population through the utilization and implementation of differentiated instructional strategies, teachers acknowledged that students could improve their proficiency levels in regards to their language and content acquisition as they move along grade levels [44]. With this in mind, there is a need for building struggling students background knowledge to set the foundation for new content. Implementation of differentiated instruction as a pre-teaching strategy should be used to address the lower third student population to assist in their acquisition of critical concepts and ideas [68].

Reference [14] argued that when learning does not occur, teachers must address the learning from the perspective of modifying the method and delivery to meet their students' needs. To effectively accomplish this endeavor, it is expected that teachers will determine the source of the problem and plan appropriately to address any missing skills [14]. Overall the findings from this study show that most of the 35 participants provided testimonies that represents extensive knowledge regarding differentiated instruction. While teacher knowledge of differentiated instruction plays a role in their perception regarding the strategy effectiveness and utilization in their classrooms, it is clear that the participants do face daily challenges in implementation. These findings further indicate that the way in which differentiated instruction is woven into individual teacher's pedagogy and how the instructional strategy is implemented by middle school teachers drives their perception of differentiated instruction effectiveness on enhancing lower third student academic achievement.

\section{Conclusion}

Participants' interviews indicate that there exists a robust perception that differentiated instruction as an instructional strategy is of utmost importance and is effective in addressing the lower third student population during the enterprise of learning. The information provided by the participants indicated an awareness of differentiated instruction role in addressing the needs of all students in the learning environment, especially those listed in the lower third population. Challenges that participants faced in utilizing and implementing differentiated instruction to address the needs of the lower third students were excessive planning time, planning rigorous lessons, and the belief that differentiated instruction was not necessary for increasing lower third student population in regards to their learning achievement.

Addressing these challenges to increase positive teacher perceptions of differentiated instruction to improve the lower third student population academic achievement, requires addressing several components. Components include raising teacher awareness of using data to drive instruction for individual students and targeted instruction must be the norm throughout the learning environment. Purposeful and strategic scheduling of extended common planning time will provide teachers with the time needed to plan appropriately for the diverse student population. Providing individual, group, and district assisted professional development on differentiated instruction strategies that are effective in addressing lower level learners' needs will also provide a bridge to the importance of differentiated instruction to address individual students needs. Administrators must engage in supporting teachers by facilitating the design of a culture that fosters teacher awareness of rigorous learning objectives that are differentiated for the diverse student population. Engaging teachers in cycles of frequent and timely feedback that focuses on addressing lower third student needs via planning and preparation of differentiated lessons is of paramount importance in laying the foundation to monitor, revise, and implement differentiated curriculum, unit and lesson plans that target content, process, and product to strengthen teachers understanding of planning differentiated lessons is desired. Finally, there is a need to foster environments of inter-visitation between veteran teachers and their peers who need additional support to enhance implementation of differentiated instruction thereby enhancing pedadogy.

The results of the study indicate that teachers' perceptions regarding the effectiveness of differentiated instruction on the academic achievement of the lower third student are paramount. To a large extent, the teacher's perceptions indicate that differentiated instruction plays a vital role in addressing the needs of all students within the learning environment. Discussions with teachers indicate a certain degree of concern regarding attitudes, knowledge, and utilization of differentiated instruction. These discussions suggests that school building leaders must create innovative 
ways to ensure the strategic scheduling of extended common planning time to afford teacher the time needed to engage in planning appropriately for the diverse student population. Planning should also include providing individual, group, and district assisted professional development on differentiated instruction strategies that are effective in addressing the needs of lower level learners to enhance their academic achievement across all content areas. While the focus is on providing pathways for student achievement, teacher perceptions of differentiated instruction must be taken into consideration as school leaders create learning environments that foster teacher awareness of rigorous learning objectives that are differentiated for the diverse student population.

Strengthening teacher's perceptions regarding the effect of differentiated instruction on the lower third student population should include cycles of frequent and timely feedback that focuses on addressing lower third student needs via planning and preparation of differentiated instruction lessons. These factors must be tightly interwoven with monitoring, revising, and implement differentiated curriculum, unit plans, and lesson plans that address content, process, and product that are specifically designed to meet individual students needs based on readiness levels. The development of an intervisitation culture between veteran teachers and new in-service teachers to provide additional support for implementing differentiated instruction to address deficiencies of the lower third students. New and in-service teachers will, therefore, receive support to increase their pedagogical knowledge of differentiated instruction as a tool to address individual student acquisition of key concepts and main ideas of content.

\section{References}

[1] Harsh, S., \& Mallory, M. (2013). The future of education: Building capacity for success. Phi Delta Kappan, 80 (1), 1625 .

[2] Parsons, S. A., Dodman, S. L., \& Cohen Burrowbridge, S. (2013). Broadening the view of differentiated instruction. Phi Delta Kappan, 95, 38-42. doi:10.1177/003172171309500107.

[3] Stolk, J., \& Harari, J. (2014). Student motivations as predictors of high-level cognitions in project-based classrooms. Active Learning in Higher Education, 15, 231247. doi:10.1177/1469787414554873.

[4] De Jesus, O. N. (2012). Differentiated Instruction: Can differentiated instruction provide success for all learners? National Teacher Education Journal, 5 (3), 5-11.

[5] Wei, X. (2012). Are more stringent NCLB state accountability systems associated with better student outcomes? Analysis of NAEP results across states. Educational Policy, 26, 268-308. doi:10.1177/0895904810386588.

[6] Dixon, F. A., Yssel, N., McConnell, J. M., \& Hardin, T. (2014). Differentiated instruction, professional development, and teacher efficacy. Journal for the Education of the Gifted, 37, 111-127. doi:10.1177/0162353214529042.
[7] Powell, W., \& Kusuma-Powell, O. (2015). Overcoming resistance to new ideas. Phi Delta Kappan, 96 (8), 66-69. Retrieved from http://pdk.sagepub.com.

[8] Cooper, K. S. (2014). Eliciting engagement in the high school classroom: A mixed-methods examination of teaching practices. American Educational Research Journal, 51, 363402. doi: 10.3102/0002831213507973.

[9] Lee, C., \& Picano, K. E. (2013). Accommodating diversity by analyzing practices of teaching (ADAPT). Teacher Education and Special Education, 36, 132-144. doi: 10.1177/0888406413483327.

[10] Little, C. A., McCoach, D. B., \& Reis, S. M. (2014). Effects of differentiated reading instruction on student achievement in middle school. Journal of Advanced Academics, 25, 384-402. doi: $10.1177 / 1932202 X 14549250$.

[11] Paige, D. D., Sizemore, J. M., \& Neace, P. W. (2013). Working inside the box: Exploring the relationship between student engagement and cognitive rigor. National Association of Secondary School Principal, 97, 105-123. doi: $10.1177 / 0192636512473505$.

[12] Woolley, M. E., Rose, R. A., Orthner, D. K., Akos, P. T., \& Jones-Sanpei, H. (2013). Advancing academic achievement through career relevance in the middle grades: A longitudinal evaluation of careerstart. American Educational Research Journal, 50, 1309-1335. doi:10.3102/0002831213488818.

[13] Jennings, J., \& Sohn, H. (2014). Measure for Measure: How proficiency-based accountability systems affect inequality in academic achievement. Sociology of Education, 87, 125-141. doi: $10.1177 / 0038040714525787$.

[14] Acosta-Tello, E., \& Shepherd, C. (2014). Equal access for all learners: Differentiation simplified. Journal of Research in Innovative Teaching, 7 (1), 51-57. Retrieved from http://jritnu.org/.

[15] Joo, Y. J., Seo, H., Joung, S., \& Lee, K. Y. (2012). The effects of academic self-efficacy, learning strategies and perceived instructional strategies on high and low achievers" in the middle school Korean language. KEDI Journal of Educational Policy, 9 (2), 239-257. Retrieved from http//:eng.kedi.re.kr.

[16] Lanier, M., \& Glasson, G. (2014). Instructional strategies for enhancing achievement for urban African American students in middle school science classrooms. Insights on Learning Disabilities, 11 (1), 9-32.

[17] No Child Left Behind Act of 2001. Pub. L. No. 107-110, § 115 Stat. 1425.

[18] Cronin, J., \& Jensen, N. (2014). The phantom collapse of student achievement in New York. Phi Delta Kappan, 96, 6066. doi: 10.1177/0031721714553412.

[19] Desimone, L. M. (2013). Reform before NCLB. Phi Delta Kappan, 94, 59-61. doi: 10.1177/003172171309400814.

[20] VanTassel-Baska, J. (2015). Arguments for and against the Common Core State Standards. Gifted Child Today, 38, 60-62. doi: $10.1177 / 1076217514556535$.

[21] VanTassel-Baska, J. (2014). Performance based assessment: The road to authentic learning for the gifted. Gifted Child Today, 37, 141-147. doi: 10.1177/1076217513509618. 
[22] Dee, T. S., Jacob, B., \& Schwartz, N. L. (2013). The effects of NCLB on school resources and practices. Educational Evaluation and Policy Analysis, 35, 252-279. doi: 10.3102/0162373712467080.

[23] Bloom, C. M., \& Owens, E. W. (2011). Principals' perception of influence on factors affecting students achievement in lowand high-achieving urban high schools. Education and Urban Society, 45, 208-233. doi: 10.1177/0013124511406916.

[24] Hill, H. C., Blazar, D., \& Lynch, K. (2015). Resources for teaching: Examining personal and institutional predictors of high quality instruction. American Educational Research Journal, 1 (4), 1-23. doi: 10.1177/2332858415617703.

[25] Leasure, J. F., \& Sanchez-Fowler, L. (2011). Teaching strategies for students with low achievement in a christian school classroom. Journal of Research on Christian Education, 20, 155-181. doi:10.1080/10656219.2011.590714.

[26] Bruce-Davis, M. N., Gubbins, E. J., Gilson, C. M., Villanueva, M., Foreman, J., \& Rubenstein, L. D. (2014). STEM high school administrators,' teachers,' and students' perceptions of curricular and instructional strategies and practices. Journal of Advanced Academics, 25, 272-306. doi: $10.1177 / 1932202 X 14527952$.

[27] Donaldson, M. L. (2013). Principals' approaches to cultivating teacher effectiveness: Constraints and opportunities in hiring, assigning, evaluating, and developing teachers. Educational Administration Quarterly, 49, 838-882. doi: 10.1177/0013161X13485961.

[28] Lee, C., \& Picano, K. E. (2013). Accommodating diversity by analyzing practices of teaching (ADAPT). Teacher Education and Special Education, 36, 132-144. doi: $10.1177 / 0888406413483327$.

[29] Nomi, T., \& Allensworth, E. M. (2013). Sorting and supporting: Why double-dose algebra led to better test scores but more course failures. American Educational Research Journal, 50, 756-788. doi: 10.3102/0002831212469997.

[30] McCombs, J. S., Kirby, S. N., \& Mariano, L. T. (2009). Ending social promotion without leaving children behind: The case of New York City. McGraw Hill. (n.d.). Retrieved August 10, 2014, from http://www.rand.org.

[31] Nelson, S. W., \& Guerra, P. L. (2014). Educators beliefs and cultural knowledge: Implications for school improvement efforts. Educational Administration Quarterly, 50, 67-95. doi: 10.3102/0034654313483907.

[32] Watts-Taffe, S., Laster, B. P., Broach, L., Marinak, B., McDonald Connor, C., \& Walker-Dalhouse, D. (2012). Differentiated Instruction: Making informed teacher decisions. The Reading Teacher, 66, 303-314. doi:10.1002/TRTR.01126.

[33] Ratcliff, N. J., Jones, C. R., Costner, R. H., Knight, C., Disney, G., Savage-Davis, E., Sheehan, H., \& Hunt. (2012). No need to wait for superman: A case study of one unique high school. Journal for the Education of the Gifted, 35, 391-411. doi: $10.1177 / 0162353212459256$.

[34] Morgan, H. (2014). Maximizing student success with differentiated learning. The Clearing House, 87, 34-38. doi: 10.1080/000998655.2013.832130.

[35] Mills, M, Monk, S., Keddie, A., Renshaw, P., Christie, P., Geelan, D., \& Gowelett, C. (2014). Differentiated learning: From policy to classroom. Oxford Review of Education, 40,
331-348. doi:10.1080/03054985.2014.911725.

[36] McDonald Connor, C., \& Morrison, F. J. (2016). Individualizing student instruction in reading: Implications for policy and practice. Policy Insights from the Behavioral and Brain Sciences, 3, 54-61. doi: 10.1177/2372732215624931.

[37] Chan, P. E., Graham-Day, K. J., Ressa, V. A., Peters, M. T., \& Konrad, M. (2014). Beyond involvement: Promoting student ownership of learning in classrooms. Intervention in School and Clinic, 50, 2014. doi: 10.1177/1053451214536039.

[38] Darrow, A. (2015). Differentiated instruction for students with disabilities: Using DI in the music classroom. General Music Today, 28, 29-32. doi: 10.11771048371314554279.

[39] Brighton, M., Moon, T. R., \& Huang, F. H. L. (2015). Advanced readers in reading first classrooms: Who was really "Left Behind?" Considerations for the field of gifted education. Journal for the Education of the Gifted, 38, 257298. doi: $10.1177 / 0162353215592501$.

[40] Alavinia, P., \& Farhady, S. (2012). Teaching vocabulary through differentiated instruction: Insights from multiple intelligences and learning styles. Modern Journal of Language Teaching Methods, 2 (4), 72-82. Retrieved from http://www.mjltm.com/.

[41] Rubin, H. J., \& Rubin, I. S. (2005). Qualitative interviewing: The art of hearing data $\left(2^{\text {nd }}\right.$ ed). Thousand Oaks, California: Sage.

[42] Webb, A. (2015). Research interviews in the scholarship of teaching and learning. Transforming Dialogues: Teaching \& Learning Journal, 8 (1), 1-8. Retrieved from http://www.kpu.ca/.

[43] Goddard, Y., Goddard, R., \& Kim, M. (2015). School instructional climate and student achievement: A examination of group norms for differentiated instruction. American Journal of Education, 122, 111-131. doi: 10.1086/683293.

[44] Firmender, J. M., Reis, S. M., \& Sweeny, S. M. (2013). Reading comprehension and fluency levels ranges across diverse classrooms: The need for differentiated reading instruction and content. Gifted Child Quarterly, 57 (1), 3-14. doi: $10.1177 / 00116986212460084$.

[45] Tomlinson, C. A. (2008). The goals of differentiated instruction. Educational Leadership, 66, 26-30. Retrieved from http://www.ascd.org/publications/educationalleadership/nov08/vol66/num03/The-Goals-ofDifferentiation.aspx.

[46] Marshall, K. (2016). Rethinking differentiated-Using teachers' time most effectively. Phi Delta Kappan, 98, 8-13. doi: 10.1177/0031721716666046.

[47] Santangelo, T., \& Tomlinson C. A., (2012). Teacher educators' perceptions and use of differentiated instructiona practices: An exploratory investigation. Action in Teacher Education, 34, 309-327. doi:10.1080/01626620.2012.717032.

[48] Berrio Matamoros, A. (2016). Differentiated Instruction in Information Literacy Courses in Urban Universities: How Flipping the Classroom Can Transform a Course and Help Reach All Students. Urban Library Journal, 22 (1). Retrieved from http://academicworks.cuny.edu/ulj/vol22/iss1/1.

[49] Tomlinson, C. A. (2015). Teaching for excellence in academically diverse classrooms. Society, 5, 203-209. doi: 10.1007/s12115-015-9888-0. 
[50] Tomlinson, C. A., \& Javius, E. (2012). Teach up for excellence. Educational Leadership, 69, 28-33. Retrieved from

http://www.ascd.org/publications/educationalleadership/feb12/ vol69/num05/Teach-Up-for-Excellence.aspx.

[51] Rock, M. L., Gregg, M., Ellis, E., \& Gable, R. A. (2008). REACH: A framework for differentiating classroom instruction. Preventing School Failure, 52 (2), 31-47. doi:10.3200/PSFL.52.2.31-47.

[52] Kanevsky, L. (2011). Deferential differentiation: What types of differentiation do students want? Gifted Child Quarterly, 55, 279-299. doi:10.1177/001698621142209.

[53] Tobin, R., \& Tippett, C. D. (2014). Possibilities and potential barriers: Learning to plan for differentiated instruction in elementary science. International Journal of Science and Mathematics, 12, 423-443. doi: 10.1007/s10763-013-9414-z.

[54] Avci, S., \& Akinoğlu, O. (2014). An examination of the practices of teachers regarding the arrangement of education according to individual differences. International Journal of Instruction, 7 (2), 191-206. Retrieved from http://e-iji.net.

[55] Turkan, S., \& DaSilva Iddings, A. C. (2012). That child is yellow: New immigrant children's conception of English language, literacy, and learners' identities in the NCLB era. Theory into Practice, 51, 273-280. doi:10.1080/00405841.2012.726055.

[56] Pham, H. L. (2012). Differentiated instruction and the need to integrate teaching and practice. Journal of College Teaching \& Learning, 9 (1), 13-20. Retrieved from http://www.cluteinstitute.com/.

[57] Tomlinson, C. (2002). Different learners, different lessons. Instructor, 112, 24-91.

[58] Tricarico, K., \& Yendol-Hoppey, D. (2012). Teaching learning through self-regulation: An exploratory study of alternatively prepared teachers' ability to plan differentiated instruction in an urban elementary school. Teacher Education Quarterly, 39 (1), 130-158. Retrieved from http://www.caddogap.com.

[59] Wu, E. H. (2013). The path to differentiation: An interview with Carol Tomlinson. Journal of Advanced Academics, 24, 125-133. doi: 10.1177/1932202X13483472.
[60] Huebner, T. A. (February 2010). What research says about differentiated instruction? Educational Leadership, 67 (5), 7981. Retrieved from http://www.ascd.org/Default.aspx.

[61] Tomlinson, C. A., \& Jarvis, J. M. (2014). Case studies of success: Supporting academic success for students with high potential from ethnic minority and economically disadvantaged backgrounds. Journal for the Education of the Gifted, 37, 191-219. doi:10.1177/0162353214540826.

[62] Tzivinkov, S., \& Papoutsaki, K. (2016). Studying teaching methods, strategies and best practices for young children with special needs. Early Child Development and Care, 186, 971980. https//:10.1080/03004430.2015.

[63] Weber, C. L., Johnson, L., \& Tripp, S. (2013). Implementing differentiation: A school's journey. Gifted Child Today, 36, 179-186. doi: 10.1177/1076217513486646.

[64] Wu, Z., \& An, S. (2016). Addressing challenges in urban teaching, learning and math using model-strategy-application with reasoning approach in linguistically and culturally diverse classrooms. Journal of Urban Learning Teaching and Research, 12, 47-60. Doi.

[65] Chen, S., \& Heron, S. S. (2014). Going against the grain: Should differentiated instruction be a normal component of professional development. International Journal of Technology in Teaching and Learning, 10 (1), 14-34. Retrieved from http://www.sicet.org/journals/ijttl/ijttl.html.

[66] Martin, P. C. (2013). Role-plating in an inclusive classroom using realistic simulation to explore differentiated instruction. Issues in Teacher Education, 22 (2), 93-106. Retrieved from http://www1.chapman.edu/ITE/.

[67] Rubenstein, L. D, Gilson, C. M., Bruce-Davis, M. N., \& Jean Gubbins, E. (2015). Teachers' reactions to pre-differentiated and enriched mathematics curricula. Journal for the Education of the Gifted, 38, 141-168. doi:10.1177/0162353215578280.

[68] Berg, J. L., \& Wehby, J. (2013). Preteaching strategies to improve student learning in content area classes. Intervention in School and Clinic, 49, 14-20. doi: $10.1177 / 1053451213480029$. 